\title{
Article \\ Symptom Prevalence of Anxiety and Depression in Older Cardiac Arrest Survivors: A Comparative Nationwide Register Study
}

\author{
Kristofer Årestedt 1,2,* Johan Israelsson ${ }^{1,3}$, Ingrid Djukanovic ${ }^{1}$, Johan Herlitz ${ }^{4}$, Jörg Carlsson ${ }^{1,3}$, \\ Suzanne Petersson ${ }^{1,5}$ and Anders Bremer 6,7 (iD
}

check for

updates

Citation: Årestedt, K.; Israelsson, J.; Djukanovic, I.; Herlitz, J.; Carlsson, J.; Petersson, S.; Bremer, A. Symptom Prevalence of Anxiety and Depression in Older Cardiac Arrest Survivors: A Comparative Nationwide Register Study. J. Clin. Med. 2021, 10, 4285.

https://doi.org/10.3390/jcm10184285

Academic Editor: Roland Bingisser

Received: 6 August 2021

Accepted: 17 September 2021

Published: 21 September 2021

Publisher's Note: MDPI stays neutral with regard to jurisdictional claims in published maps and institutional affiliations.

Copyright: (c) 2021 by the authors. Licensee MDPI, Basel, Switzerland. This article is an open access article distributed under the terms and conditions of the Creative Commons Attribution (CC BY) license (https:/ / creativecommons.org/licenses/by/ $4.0 /)$.
1 Faculty of Health and Life Sciences, Linnaeus University, SE-39182 Kalmar, Sweden; johan.israelsson@regionkalmar.se (J.I.); ingrid.djukanovic@lnu.se (I.D.); jorg.carlsson@regionkalmar.se (J.C.); suzanne.petersson@regionkalmar.se (S.P.)

2 The Research Section, Region Kalmar County, Box 601, SE-39126 Kalmar, Sweden

3 Section of Cardiology, Department of Internal Medicine, Region Kalmar County, Box 601, SE-39126 Kalmar, Sweden

4 Faculty of Caring Science, Work Life and Social Welfare, University of Borås, SE-50190 Borås, Sweden; johan.herlitz@hb.se

5 Department of Rehabilitation, Region Kalmar County, Box 601, SE-39126 Kalmar, Sweden

6 Faculty of Health and Life Sciences, Linnaeus University, SE-35195 Växjö, Sweden; anders.bremer@lnu.se

7 Department of Ambulance Service, Region Kalmar County, Box 601, SE-39126 Kalmar, Sweden

* Correspondence: kristofer.arestedt@lnu.se; Tel.: +46-(0)703426325

\begin{abstract}
Knowledge about psychological distress in older cardiac arrest (CA) survivors is sparse, and the lack of comparisons with general populations make it difficult to draw any strong conclusions about prevalence and potential changes caused by CA. Our aim was to compare psychological distress between older CA survivors and a general population. This study included survivors $65-80$ years old and an age- and sex-matched general population. Data on survivors was collected from the Swedish Register of Cardiopulmonary Resuscitation. The Hospital Anxiety and Depression Scale was used to measure psychological distress. Data were analyzed with non-parametric statistics. The final sample included 1027 CA survivors and 1018 persons from the general population. In both groups, the mean age was 72 years $(\mathrm{SD}=4)$ and $28 \%$ were women. The prevalence of anxiety was $9.9 \%$ for survivors and $9.5 \%$ for the general population, while the corresponding prevalence for depression was $11.3 \%$ and $11.5 \%$ respectively. Using the cut-off scores, no significant differences between the groups were detected. However, CA survivors reported significantly lower symptom levels using the subscale scores $(\Delta \mathrm{Mdn}=1, p<0.001)$. In conclusion, the CA survivors did not report higher symptom levels of anxiety and depression than the general population. However, since psychological distress is related to poor quality-of-life and recovery, screening for psychological distress remains important.
\end{abstract}

Keywords: aged; anxiety; depression; heart arrest; psychological distress

\section{Introduction}

Cardiac arrest (CA) is a common health problem worldwide, especially in older people. In Europe, approximately 350,000 suffer out-of-hospital cardiac arrest (OHCA) annually [1,2], while the incidence of in-hospital cardiac arrest (IHCA) is estimated as 1-5 per 1000 hospital admissions [3,4]. The prognosis is poor, but the survival rates have improved during recent decades [5]. The increased number of survivors has drawn further attention to shortcomings in care and the need for evidence-based practice. Identification and treatment of psychological distress is of great importance, since such problems have an impact on health state, quality of life, and mortality [6,7]. According to the American Psychological Association, psychological distress is a state of emotional suffering characterized by symptoms of anxiety and depression, ranging from normal fluctuations 
to psychopathology. Psychological distress is often assessed by putative self-reported measures [8].

Psychological distress is commonly reported in CA survivors [9,10]. A review study by Wilder Schaaf et al. reported a prevalence of $13-61 \%$ for symptoms of anxiety and $14-45 \%$ for symptoms of depression in OHCA survivors [9]. The prevalence of psychological distress in IHCA survivors has not been studied to the same extent, however a Swedish register study by Israelsson et al. reported a prevalence of $15 \%$ and $13 \%$ for symptoms of anxiety and depression, respectively [11]. The variations in prevalence across studies can probably be explained by heterogeneity in the inclusion criteria, definitions, and measures. However, these studies have not determined if psychological distress is a consequence of suffering a cardiac arrest. In addition, there is a lack of comparison studies including general populations.

Anxiety and depression are common in older people in general [12-15]. The average age among those suffering cardiac arrest varies between countries and studies, but a mean age of 65 years or higher is commonly reported [2,16]. Despite this, existing studies about psychological distress are commonly based on age-heterogeneous samples [9]. However, CA probably affects people's lives differently during the life cycle, leading to a need for studies focusing on psychological distress in older CA survivors.

In summary, the knowledge about psychological distress in older CA survivors is sparse and the lack of comparisons with general populations make it difficult to draw any strong conclusions about prevalence and potential changes caused by the CA. Therefore, the aim of this study was to compare psychological distress between older CA survivors and an age- and sex-matched general population.

\section{Materials and Methods}

\subsection{Design}

This comparative study was based on data from the Swedish Register of Cardiopulmonary Resuscitation (SRCR) collected between 2014 and 2017 and an age- and sexmatched sample from a cross-sectional survey including a random sample of individuals from the total Swedish population in the age group 65-80 years [13]. Ethical approval was obtained from the Regional Ethical Review Board in Stockholm, Sweden (No. 2010/823314/4, No. 2017/7988-32).

\subsection{Sample and Procedure}

The inclusion of CA survivors was performed using register data from the SRCR. This registry covers a vast majority of CAs in Sweden. Data for the SRCR is collected at three times: (1) at the time of the arrest, (2) 30-days post arrest, and (3) 3-6 months post arrest. The first and second registrations include information about, for example, prearrest conditions, aetiology, treatments, survival, and neurological function (Cerebral Performance Category scale $=\mathrm{CPC}$ ). Inclusion criteria for the third registration are to be alive 3-6 months after the $C A$ and $\geq 18$ years of age. Unwillingness to participate, severe cognitive dysfunction and language difficulties are criteria for exclusion. An invitation to a telephone follow-up interview is offered and a questionnaire is sent to all CA survivors who conform to the selection criteria. The questionnaire includes the Hospital Anxiety and Depression Scale (HADS) and other patient reported outcome measures. The CA survivors receive instructions to complete the questionnaire during the interview, which is performed by resuscitation coordinators or cardiac rehabilitation nurses. The present study included CA survivors 65 to 80 years old, registered between 2014 and 2017. During this period, the response rate for all CA survivors was $56 \%$.

The general population sample was taken from a national survey investigating psychological distress in the age group $65-80$ years. The survey was conducted as a postal questionnaire including demographic data and symptoms of anxiety and depression measured with HADS. In total, 6659 randomly selected participants were included during 2010. More details of the study are presented in Djukanovic et al. [13]. To make the two samples 
comparable, the samples were stratified according to sex and age (five-year intervals). Participants from the general population sample were then randomly selected from each stratum to reach equal distributions of age and sex between the two samples.

\subsection{Measures}

The HADS is a self-rating scale developed to assess psychological distress in nonpsychiatric patients and consists of two subscales, anxiety (HADS-A) and depression (HADS-D) [17]. The HADS consists of 14 items, seven for measuring symptoms of anxiety and seven for symptoms of depression. Each item is scored on a response-scale with four alternatives, ranging from 0 to 3 . The item responses within each subscale are summarized to a total score with a possible range between 0 and 21. A higher score indicates a more severe problem with anxiety and/or depression. Snaith has recommended the following cut-off scores: 0-7 normal range, 8-10 suggested presence of mood disorder (minor problems), and 11-21 probable presence of mood disorder (moderate to major problems) [18]. The HADS is not validated in CA survivors but is recommended by the American Heart Association [19] and the European Resuscitation Council [3] to screen for symptoms of anxiety and depression among these patients. It has also demonstrated satisfactory measurement properties in related groups, e.g., patients with heart disease [20] and general populations of elderly people [21]. The subscale scores with respective cut-off scores were used in the present study. In CA survivors, internal consistency as measured by Cronbach's alpha was 0.89 for HADS anxiety and 0.85 for HADS depression in the present study. The corresponding alpha values for the general population used in this study were 0.85 and 0.81 , respectively.

\subsection{Statistical Analyses}

The CA survivors had no missing data in HADS. In contrast, 57 observations from the general population had missing data, ranging from 1 to 14 missing values. Missing data were imputed using the subscale half mean procedure recommended by Bell et al. [22], i.e., data were replaced using person mean score in observations with $\leq 3$ missing values for each subscale, respectively. In total, 80 missing values were imputed for 48 observations. Consequently, nine observations were excluded. Thus, the statistical analyses regarding HADS were conducted on 1027 CA survivors and 1018 persons from the general population.

Descriptive statistics were used to present sample characteristics and symptoms of anxiety and depression. The independent sample t-test and Pearson chi-square test were conducted to compare differences in age and gender between the CA survivors and the general population.

In order to compare differences in psychological distress, the analyses were conducted in two steps. In the first step, both IHCA and OHCA survivors were treated as one group and compared with the general population. Based on the HADS subscale scores, the Mann-Whitney $U$ test was used to compare differences in anxiety and depression. With HADS subscales grouped into three categories (normal, suggested and probable presence of anxiety and depression), the Pearson chi-square test was used. In the second step, CA survivors were regrouped by IHCA and OHCA and compared with the general population. Based on the HADS subscale scores, the Kruskal-Wallis test was conducted to compare differences in psychological distress between the three groups. The Mann-Whitney U test was used as a post-hoc test and the Bonferroni correction was applied to reduce the likelihood of wrongly rejecting the null hypothesis (i.e., type I error). The Pearson chisquare test was conducted to compare differences in anxiety and depression between the three groups, using the same categorization of the HADS subscale described above.

The level of statistical significance was set at $p<0.05$, except for the Bonferroni correction in the post-hoc analyses where the significance level was set at $p<0.017$. All statistical analyses were conducted in Stata 16.1 (StataCorp LLC, College Station, TX, USA). 


\section{Results}

\subsection{Sample Characteristics}

The characteristics of the participants are presented in Table 1. The mean age was 71.9 $(\mathrm{SD}=4.4)$ in the $\mathrm{CA}$ survivors and $71.8(\mathrm{SD}=4.4)$ in the general population. The gender distribution was equal in both groups, with $736(71.7 \%)$ men and $291(28.3 \%)$ women in the CA survivors and $730(71.7 \%)$ men and $288(28.3 \%)$ women in the general population. No significant difference was shown in age $(p=0.66)$ or sex $(p=0.98)$ between the groups. A majority of the survivors had suffered IHCA $(n=694,67.6 \%)$, had a cardiac aetiology ( $n=746,72.6 \%$ ), had a shockable initial rhythm (ventricular fibrillation or ventricular tachycardia, $n=608,59.2 \%)$, and were defibrillated ( $n=636,61.9 \%)$. The CA was witnessed in 956 cases $(93.1 \%)$. The most common place for OHCA was the survivor's own home $(n=140,42.0 \%)$, while the most common places for IHCA were heart intensive care units ( $n=165,23.8 \%)$ and general wards $(n=165,23.8 \%)$. According to the CPC scale, most survivors had good neurological function (CPC 1$)$ at inclusion $(n=886,86.3 \%)$.

Table 1. Sample characteristics.

\begin{tabular}{|c|c|c|c|}
\hline & $\begin{array}{c}\text { CA Survivors, } \\
n=1027\end{array}$ & $\begin{array}{c}\text { General Population, } \\
n=1018\end{array}$ & $p$-Value \\
\hline Age, mean (SD) & $71.9(4.4)$ & $71.8(4.4)$ & 0.658 \\
\hline Sex, $n(\%)$ & & & 0.982 \\
\hline Woman & $291(28.3)$ & $288(28.3)$ & \\
\hline Man & $736(71.7)$ & $730(71.7)$ & \\
\hline \multicolumn{4}{|l|}{ Etiology, $n(\%)$} \\
\hline Cardiac & $746(72.6)$ & & \\
\hline Other & $268(26.1)$ & & \\
\hline Unknown & $13(1.3)$ & & \\
\hline \multicolumn{4}{|l|}{ Initial rhythm, $n(\%)$} \\
\hline $\mathrm{VF} / \mathrm{VT}$ & $608(59.2)$ & & \\
\hline PEA & $95(9.3)$ & & \\
\hline Asystole & $156(15.2)$ & & \\
\hline Unknown & $168(16.4)$ & & \\
\hline \multicolumn{4}{|l|}{$\begin{array}{c}\text { Place of CA, } n(\%) \\
\text { IHCA }\end{array}$} \\
\hline Heart intensive care unit & $165(16.1)$ & & \\
\hline Angiography laboratory & $143(13.9)$ & & \\
\hline Intensive care unit & $60(5.8)$ & & \\
\hline Emergency care unit & $82(8.0)$ & & \\
\hline Intermediate care & $7(0.7)$ & & \\
\hline Surgical ward & $21(2.0)$ & & \\
\hline General ward & $165(16.1)$ & & \\
\hline Reception ward & $33(3.2)$ & & \\
\hline Other within hospital & $18(1.8)$ & & \\
\hline OHCA & & & \\
\hline $\begin{array}{l}\text { Home } \\
\text { Publiclace }\end{array}$ & $140(13.6)$ & & \\
\hline Public place & 122 (11.9) & & \\
\hline Other out of hospital & $71(6.9)$ & & \\
\hline \multicolumn{4}{|l|}{ Witnessed, $n(\%)$} \\
\hline Yes & $956(93.1)$ & & \\
\hline No & $62(6.0)$ & & \\
\hline Unknown & $9(0.9)$ & & \\
\hline \multicolumn{4}{|l|}{ Defibrillation, $n(\%)$} \\
\hline Yes & $636(61.9)$ & & \\
\hline No & $384(37.4)$ & & \\
\hline Unknown & $7(0.7)$ & & \\
\hline \multicolumn{4}{|l|}{ CPC at inclusion, $n(\%)$} \\
\hline CPC 1 (good performance) & $886(86.3)$ & & \\
\hline CPC 2 (moderate disability) & 110 (10.7) & & \\
\hline CPC 3 (severe disability) & $20(2.0)$ & & \\
\hline Unknown & $11(1.1)$ & & \\
\hline
\end{tabular}

$\overline{\mathrm{CA}}=$ cardiac arrest; $\mathrm{CPC}=$ cerebral performance category; $\mathrm{IHCA}=$ in-hospital cardiac arrest; $\mathrm{OHCA}=$ out-ofhospital cardiac arrest; PEA = pulseless electrical activity; VT/VF = ventricular tachycardia/ventricular fibrillation. 


\subsection{Comparisons of Psychological Distress between CA Survivors and the General Population}

No significant differences were detected between CA survivors and the general population using the cut-off scores for anxiety $(p=0.701)$ and depression $(p=0.703)$. Of the CA survivors, $9.9 \%(n=102)$ reported suggested or probable presence of anxiety and $11.5 \%(n=118)$ reported suggested or probable presence of depression. The corresponding prevalence in the general population was $9.5 \%(n=97)$ for anxiety and $11.3 \%(n=115)$ for depression (Table 2).

Table 2. Comparisons of psychological distress between cardiac arrest survivors and a general population matched for age and sex.

\begin{tabular}{cccc}
\hline & $\begin{array}{c}\text { CA Survivors, } \\
\boldsymbol{n}=\mathbf{1 0 2 7}\end{array}$ & $\begin{array}{c}\text { General Population, } \\
\boldsymbol{n}=\mathbf{1 0 1 8}\end{array}$ & $\boldsymbol{p}$-Value \\
\hline Anxiety score, Mdn (q1-q3) & $1(0-4)$ & $2(1-5)$ & $<0.001^{\mathrm{a}}$ \\
\hline Anxiety categorized, $n$ (\%) & & & $0.701^{\mathrm{b}}$ \\
Normal range (scores 0-7) & $925(90.1)$ & $921(90.5)$ & \\
Suggested presence (scores 8-10) & $64(6.2)$ & $66(6.5)$ & \\
Probable presence (scores 11-21) & $38(3.7)$ & $31(3.0)$ & \\
\hline Depression score, Mdn (q1-q3) & $2(0-4)$ & $3(1-5)$ & \\
\hline Depression categorized, $n$ (\%) & & & \\
Normal range (scores 0-7) & $909(88.5)$ & $903(88.7)$ & \\
Suggested presence (scores 8-10) & $75(7.3)$ & $79(7.8)$ & \\
Probable presence (scores 11-21) & $43(4.2)$ & $36(3.5)$ & \\
\hline
\end{tabular}

$\mathrm{CA}=$ cardiac arrest; ${ }^{\mathrm{a}}$ Mann-Whitney $\mathrm{U}$ test; $^{\mathrm{b}}$ Pearson chi-square test.

Based on the HADS subscale scores, both CA survivors and the general population generally reported low levels of both anxiety and depression. The general population reported significantly higher levels of symptoms in both anxiety $(\Delta \mathrm{Mdn}=1, p<0.001)$ and depression $(\Delta \mathrm{Mdn}=1, p<0.001)$ compared with the CA survivors (Table 2$)$.

3.3. Comparisons of Psychological Distress between IHCA Survivors, OHCA Survivors, and the General Population

No significant differences were detected between IHCA survivors, OHCA survivors, and the general population using the cut-off scores for anxiety $(p=0.190)$ and depression $(p=0.489)$. Of the IHCA survivors, $11.4 \%(n=79)$ reported suggested or probable presence of anxiety and $12.5 \%(n=87)$ reported suggested or probable presence of depression. The corresponding prevalence in OHCA survivors was $6.9 \%(n=23)$ for anxiety and $9.3 \%$ $(n=31)$ for depression (Table 3).

The comparison of the HADS subscale scores between IHCA survivors, OHCA survivors and the general population showed significant differences overall in anxiety $(\Delta \mathrm{Mdn}=1, p<0.001)$ and depression $(\Delta \mathrm{Mdn}=2, p<0.001)$ between the three groups. The post hoc analysis showed that the general population scored significantly higher symptom levels in both anxiety and depression compared with OHCA and IHCA survivors. In addition, IHCA survivors scored significantly higher symptom levels in anxiety and depression compared with OHCA survivors (Table 3). 
Table 3. Comparisons of psychological distress between in-hospital cardiac arrest survivors, out-of-hospital cardiac arrest survivors and a general population matched for age and sex.

\begin{tabular}{|c|c|c|c|c|c|}
\hline & $\begin{array}{c}\text { Survivors, IHCA, } \\
\quad n=694\end{array}$ & $\begin{array}{l}\text { Survivors, OHCA, } \\
\qquad n=333\end{array}$ & $\begin{array}{c}\text { General } \\
\text { Population, } \\
n=1018\end{array}$ & $p$-Value & $\begin{array}{c}\text { Post-Hoc } \\
\text { Test }^{+}\end{array}$ \\
\hline Anxiety score, Mdn (q1-q3) & $2(0-5)$ & $1(0-3)$ & $2(1-5)$ & $<0.001^{a}$ & $\mathrm{ABC}$ \\
\hline Anxiety categorized, $n(\%)$ & & & & $0.190^{\mathrm{b}}$ & \\
\hline Normal range (scores 0-7) & $615(88.6)$ & $310(93.1)$ & $921(90.5)$ & & \\
\hline Suggested presence (scores 8-10) & $51(7.4)$ & $13(3.9)$ & $66(6.5)$ & & \\
\hline Probable presence (scores 11-21) & $28(4.0)$ & $10(3.0)$ & $31(3.0)$ & & \\
\hline Depression score, Mdn (q1-q3) & $2(1-5)$ & $1(0-3)$ & $3(1-5)$ & $<0.001^{\mathrm{a}}$ & $\mathrm{ABC}$ \\
\hline Depression categorized, $n(\%)$ & & & & $0.489^{b}$ & \\
\hline Normal range (scores $0-7$ ) & $607(87.5)$ & $302(90.7)$ & $903(88.7)$ & & \\
\hline Suggested presence (scores 8-10) & $57(8.2)$ & $18(5.4)$ & $79(7.8)$ & & \\
\hline Probable presence (scores 11-21) & $30(4.3)$ & $13(3.9)$ & $36(3.5)$ & & \\
\hline
\end{tabular}

IHCA = in-hospital cardiac arrest; OHCA = out-of-hospital cardiac arrest; ${ }^{\text {a }}$ Mann-Whitney $\mathrm{U}$ test; ${ }^{\mathrm{b}}$ Pearson chi-square test. ${ }^{\dagger}$ Post-hoc test based on Mann-Whitney $\mathrm{U}$ test with Bonferroni corrected $p$-values $(p<0.017)$ : A = IHCA vs. OHCA, B = IHCA vs. general population, $\mathrm{C}=\mathrm{OHCA}$ vs. general population .

\section{Discussion}

To the best of our knowledge, this is the first large study that has compared psychological distress between older CA survivors and a general population matched for age and sex. Overall, the present study showed that the CA survivors reported lower or equal levels of psychological distress compared with the general population.

Using the HADS subscale scores, CA survivors reported significantly lower symptom levels in both anxiety and depression. However, the effect size was small and no differences were detected using the cut-off scores. This indicates that the differences between the two groups are related to the lower end of the subscales, i.e., the part of the scale that is defined as the normal range by Snaith [18]. Our findings may implicate problems with using $\geq 8$ as a cut-off score in CA survivors. A review by Bjelland et al. [23] shows that different cut-off scores have been suggested for HADS across studies and in different samples. They concluded that values $\geq 8$ are commonly recommended, but they also showed that lower cut-off scores can be of importance. Individual studies in the review suggested $\geq 3$ for anxiety in primary care [24] and $\geq 4$ for depression in post stroke care [25]. We have also previously reported that one single question about anxiety/depression in EQ-5D-5L identified a higher prevalence of psychological distress compared with $\geq 8$ as a cut-off score for HADS [11]. Lack of evidence of a clinically relevant cut-off score for CA survivors may result in poor sensitivity and specificity, and further studies are therefore needed. Until then, HADS subscale scores should be reported in addition to the cut-off scores.

The CA survivors did not report more problems with anxiety and depression compared with the general population. These results are partly supported by a previous study by Israelsson et al. who reported equal levels of psychological distress, measured by a single item from EQ-5D, in ICD-implanted CA survivors and an age matched general population. They also found that the CA survivors reported better general health [26]. Similar findings have also been reported in other patient groups who have survived a life-threatening illness, for example cancer [27]. One possible explanation could be gratitude towards being alive and a re-evaluation of living-preferences [28,29]. In addition, after the first European guidelines for post CA follow-up care were published in 2015 [30], improvements in care might also have contributed by improving the screening for psychological distress and referral to specialized psychological care when needed. In contrast, people from the general population need to seek help themselves, and it is well known that stigma is an important barrier for help-seeking [31]. For example, a population-based study of older persons in Sweden showed that only $2.9 \%$ of those who scored suggested or probable presence of depression using HADS visited a psychologist [13]. However, 
these mechanisms are not well explored in CA survivors, and the interpretation of the findings are complicated by the fact that few studies have data on psychological distress prior to CA.

It is important to remember that the present study included only older CA survivors and the mean age was therefore high compared with previous studies. Thus, the findings from the present study might not be comparable with studies that also included younger CA survivors. For example, in the present study both the CA survivors and the general population reported a higher prevalence of depression than anxiety. This is in contrast to studies reporting similar [32] or higher prevalence of anxiety compared with depression in CA survivors [10]. Hence, the state of knowledge is unclear and there is a need for further studies on the potential importance of age in relation to anxiety and depression in this group. However, as previous studies have shown that psychological distress is associated with recovery and quality of life $[10,33]$, the importance of screening remains.

\section{Methodological Limitations}

The present study has some important limitations that need to be considered. We used data from one of the largest Swedish surveys in order to have a valid comparison group representing a general population of older people in Sweden. Since the survey was restricted to people 65 to 80 years old, CA survivors in the same age span were included. The age of 65 years is commonly used in studies of older people in Sweden, since this is the official age for retirement. However, the upper restriction of 80 years is somewhat problematic, as the findings will not reflect the situation among older people.

The response rate for all CA survivors in the SRCR during 2014-2017 was 56\%, and along with the unwillingness of some survivors to participate in the study, selection bias can thus not be excluded. Data collection for the SRCR requires that the survivors themselves can read and complete the self-reported instruments, which excludes persons with severe cognitive decline. Since cognitive impairments are common in CA survivors [34], and are also related to mental health [10], it is likely that psychological distress in this group is underestimated. However, this possible selection bias is probably present in the general population as well, since data collection was conducted in a similar way with postal questionnaires. Related to this, the lack of sufficient background data on both groups, such as co-morbidity and socioeconomic situation, implies uncertainty regarding group comparability. Thus, the findings should be generalized with some caution.

In the present study, symptoms of anxiety and depression were measured as two separate aspects of psychological distress. Generally, anxiety and depression have a high degree of symptom overlap, and co-morbidity with other affective or mood disorders is common. About $50 \%$ of those with an anxiety or depression diagnosis have shown to have one or more additional affective/mood diagnoses [35,36]. It has also been suggested that different symptoms of psychiatric distress could be various expressions for one disorder [37]. Despite this, the HADS is widely used with its two original scales and has thus shown good psychometric properties [21,23]. Different cut-off scores have been suggested in previous research studies. In the present study, we used one of the most common cut-off scores for the HADS, as suggested by its creator $[18,23]$. However, the instrument and the cut-off scores have not been validated in CA survivors. This is a limitation for the present study, as it is for other CA studies based on HADS.

\section{Conclusions}

Previous research studies have often described psychological distress as a common problem in CA survivors, and screening is recommended in international clinical guidelines. However, when using a general population comparison group, the survivors in the present study did not report higher symptom levels of anxiety or depression. Since psychological distress is related to poor quality of life and recovery, it is important from a clinical perspective to identify CA survivors with these problems. Thus, screening for psychological distress remains important. 
Author Contributions: Conceptualization, K.Å., J.I., I.D., J.H., J.C., S.P. and A.B.; Methodology, K.Å., J.I., I.D. and A.B.; Software, K.Å.; Validation, K.Å.; Formal Analysis, K.Å.; Investigation, K.Å., J.I., I.D., J.H. and A.B.; Resources, I.D.; Data Curation, K.Å. and I.D.; Writing-Original Draft Preparation, K.A., J.I., I.D. and A.B.; Writing-Review \& Editing, K.Å., J.I., I.D., J.H., J.C., S.P. and A.B.; Project Administration, K.Å. All authors have read and agreed to the published version of the manuscript.

Funding: This research received no external funding.

Institutional Review Board Statement : Ethical approval was obtained from the Regional Ethical Review Board in Stockholm, Sweden (No. 2010/823-314/4, No. 2017/7988-32).

Informed Consent Statement: Informed consent was obtained from all participants.

Data Availability Statement: Data are available from the Swedish Register of Cardiopulmonary Resuscitation (SRCR) and the corresponding author upon reasonable request.

Acknowledgments: We would like to thank all survivors who have contributed to the present study by sharing their experiences with the Swedish Register of Cardiopulmonary Resuscitation.

Conflicts of Interest: The authors declare no conflict of interest.

\section{References}

1. Berdowski, J.; Berg, R.A.; Tijssen, J.G.; Koster, R.W. Global incidences of out-of-hospital cardiac arrest and survival rates: Systematic review of 67 prospective studies. Resuscitation 2010, 81, 1479-1487. [CrossRef]

2. Gräsner, J.T.; Wnent, J.; Herlitz, J.; Perkins, G.D.; Lefering, R.; Tjelmeland, I.; Koster, R.W.; Masterson, S.; Rossell-Ortiz, F.; Maurer, H.; et al. Survival after out-of-hospital cardiac arrest in Europe-Results of the EuReCa TWO study. Resuscitation 2020, 148, 218-226. [CrossRef] [PubMed]

3. Nolan, J.P.; Soar, J.; Smith, G.B.; Gwinnutt, C.; Parrott, F.; Power, S.; Harrison, D.A.; Nixon, E.; Rowan, K.; National Cardiac Arrest Audit. Incidence and outcome of in-hospital cardiac arrest in the United Kingdom National Cardiac Arrest Audit. Resuscitation 2014, 85, 987-992. [CrossRef] [PubMed]

4. Radeschi, G.; Mina, A.; Berta, G.; Fassiola, A.; Roasio, A.; Urso, F.; Penso, R.; Zummo, U.; Berchialla, P.; Ristagno, G.; et al. Incidence and outcome of in-hospital cardiac arrest in Italy: A multicentre observational study in the Piedmont Region. Resuscitation 2017, 119, 48-55. [CrossRef]

5. Chan, P.S.; McNally, B.; Tang, F.; Kellermann, A. Recent trends in survival from out-of-hospital cardiac arrest in the United States. Circulation 2014, 130, 1876-1882. [CrossRef]

6. Jongenelis, K.; Pot, A.M.; Eisses, A.M.H.; Beekman, A.T.F.; Kluiter, H.; Ribbe, M.W. Prevalence and risk indicators of depression in elderly nursing home patients: The AGED study. J. Affect. Disord. 2004, 83, 135-142. [CrossRef] [PubMed]

7. Mohlman, J.; Bryant, C.; Lenze, E.J.; Melinda, M.A.; Gum, A.; Flint, A.; Beekman, A.T.F.; Loebach Wetherell, J.; Thorp, S.R.; Craske, M.G. Improving recognition of late life anxiety disorders in Diagnostic and Statistical Manual of Mental Disorders: Observations and recommendations of the Advisory Committee to the Lifespan Disorders Work Group. Int J Geriatr Psychiatry 2012, 27, 549-556. [CrossRef] [PubMed]

8. American Psychological Association, Dictionary of Psychology. Available online: https:/ /dictionary.apa.org (accessed on 25 January 2021).

9. Wilder Schaaf, K.P.; Artman, L.K.; Peberdy, M.A.; Walker, W.C.; Ornato, J.P.; Gossip, M.R.; Kreutzer, J.S.; For the Virginia Commonwealth University ARCTIC Investigators. Anxiety, depression, and PTSD following cardiac arrest: A systematic review of the literature. Resuscitation 2013, 84, 873-877. [CrossRef] [PubMed]

10. Lilja, G.; Nilsson, G.; Nielsen, N.; Friberg, H.; Hassager, C.; Koopmans, M.; Kuiper, M.; Martini, A.; Mellinghoff, J.; Pelosi, P.; et al. Anxiety and depression among out-of-hospital cardiac arrest survivors. Resuscitation 2015, 97, 68-75. [CrossRef]

11. Israelsson, J.; Bremer, A.; Herlitz, J.; Axelsson, Å.B.; Cronberg, T.; Djärv, T.; Kristofferzon, M.-L.; Larsson, I.-M.; Lilja, G.; Sunnerhagen, K.S.; et al. Health status and psychological distress among in-hospital cardiac arrest survivors in relation to gender. Resuscitation 2017, 114, 27-33. [CrossRef]

12. Castro-Costa, E.; Dewey, M.; Stewart, R.; Banerjee, S.; Huppert, F.; Mendoloca-Lima, C.; Bula, C.; Reisches, F.; Wancata, J.; Ritchie, K.; et al. Prevalence of depressive symptoms and syndromes in later life in ten European countries The SHARE study. Br. J. Psychiatry 2007, 191, 393-401. [CrossRef]

13. Djukanović, I.; Sorjonen, K.; Peterson, U. Association between depressive symptoms and age, sex, loneliness and treatment among older people in Sweden. Aging Ment. Health 2015, 19, 560-568. [CrossRef] [PubMed]

14. Bryant, C.; Jackson, H.; Ames, D. The prevalence of anxiety in older adults: Methodological issues and a review of the literature. J. Affect. Disord. 2008, 109, 233-250. [CrossRef] [PubMed]

15. Byers, A.L.; Yaffe, K.; Covinsky, K.E.; Friedman, M.B.; Bruce, M.L. High occurrence of mood and anxiety disorders among older adults: The National Comorbidity Survey Replication. Arch. Gen. Psychiatry 2010, 67, 489-496. [CrossRef] [PubMed]

16. Churpek, M.M.; Yuen, T.C.; Winslow, C.; Hall, J.; Edelson, D.P. Differences in vital signs between elderly and non-elderly patients prior to ward cardiac arrest. Crit. Care Med. 2015, 43, 816-822. [CrossRef] [PubMed] 
17. Zigmond, A.S.; Snaith, R.P. The Hospital Anxiety and Depression scale. Acta Psychiatr Scand 1983, 67, 361-370. [CrossRef]

18. Snaith, R.P. The hospital anxiety and depression scale. Health Qual. Life Outcomes 2003, 1, 29. [CrossRef]

19. Sawyer, K.N.; Camp-Rogers, T.R.; Kotini-Shah, P.; Del Rios, M.; Gossip, M.R.; Moitra, V.K.; Haywood, K.L.; Dougherty, C.M.; Lubitz, S.A.; Rabinstein, A.A.; et al. Sudden cardiac arrest survivorship: A scientific statement from the American Heart Association. Circulation 2020, 141, e654-e685. [CrossRef]

20. Martin, C.R.; Thompson, D.R. A psychometric evaluation of the Hospital Anxiety and Depression Scale in coronary care patients following acute myocardial infarction. Psychol. Health Med. 2000, 5, 193-201. [CrossRef]

21. Djukanovic, I.; Carlsson, J.; Årestedt, K. Is the Hospital Anxiety and Depression Scale (HADS) a valid measure in a general population 65-80 years old? A psychometric evaluation study. Health Qual. Life Outcomes 2017, 15, 193. [CrossRef]

22. Bell, M.L.; Fairclough, D.L.; Fiero, M.H.; Butow, P.N. Handling missing items in the Hospital Anxiety and Depression Scale (HADS): A simulation study. BMC Res. Notes 2016, 9, 479. [CrossRef] [PubMed]

23. Bjelland, I.; Dahl, A.A.; Haug, T.T.; Neckelmann, D. The validity of the Hospital Anxiety and Depression Scale. An updated literature review. J. Psychosom. Res. 2002, 52, 69-77. [CrossRef]

24. Lam, C.L.; Pan, P.C.; Chan, A.W.; Chan, S.Y.; Munro, C. Can the Hospital Anxiety and Depression (HAD) Scale be used on Chinese elderly in general practice? Fam. Pract. 1995, 12, 149-154. [CrossRef] [PubMed]

25. Johnson, G.; Burvill, P.W.; Anderson, C.S.; Jamrozik, K.; Stewart-Wynne, E.G.; Chakera, T.M. Screening instruments for depression and anxiety following stroke: Experience in the Perth community stroke study. Acta Psychiatr. Scand. 1995, 91, 252-257. [CrossRef]

26. Israelsson, J.; Thylén, I.; Strömberg, A.; Bremer, A.; Årestedt, K. Factors associated with health-related quality of life among cardiac arrest survivors treated with an implantable cardioverter-defibrillator. Resuscitation 2018, 132, 78-84. [CrossRef] [PubMed]

27. Annunziata, M.A.; Muzzatti, B.; Flaiban, C.; Gipponi, K.; Carnaghi, C.; Tralongo, P.; Caruso, M.; Cavina, R.; Tirelli, U. Long-term quality of life profile in oncology: A comparison between cancer survivors and the general population. Support. Care Cancer 2018, 26, 651-656. [CrossRef] [PubMed]

28. Bremer, A.; Dahlberg, K.; Sandman, L. To survive out-of-hospital cardiac arrest: A search for meaning and coherence. Qual. Health Res. 2009, 19, 323-338. [CrossRef]

29. Forslund, A.S.; Jansson, J.H.; Lundblad, D.; Söderberg, S. A second chance at life: People's lived experiences of surviving out-of-hospital cardiac arrest. Scand. J. Caring Sci. 2017, 31, 878-886. [CrossRef] [PubMed]

30. Nolan, J.P.; Soar, J.; Cariou, A.; Cronberg, T.; Moulaert, V.R.M.; Deakin, C.D.; Bottiger, B.W.; Friberg, H.; Sunde, K.; Sandroni, C. European Resuscitation Council and European Society of Intensive Care Medicine guidelines for post-resuscitation care 2015: Section 5 of the European Resuscitation Council guidelines for resuscitation 2015. Resuscitation 2015, 95, 202-222. [CrossRef]

31. Corrigan, P. How stigma interferes with mental health care. Am. Psychol. 2004, 59, 614-625. [CrossRef]

32. Djärv, T.; Bremer, A.; Herlitz, J.; Israelsson, J.; Cronberg, T.; Lilja, G.; Rawshani, A.; Årestedt, K. Health-related quality of life after surviving an out-of-hospital compared to an in-hospital cardiac arrest: A Swedish population-based registry study. Resuscitation 2020, 151, 77-84. [CrossRef] [PubMed]

33. Presciutti, A.; Sobczak, E.; Sumner, J.A.; Roh, D.J.; Park, S.; Claassen, J.; Kronish, I.; Agarwal, S. The impact of psychological distress on long-term recovery perceptions in survivors of cardiac arrest. J. Crit. Care 2019, 50, 227-233. [CrossRef]

34. Moulaert, V.R.; Verbunt, J.A.; van Heugten, C.M.; Wade, D.T. Cognitive impairments in survivors of out-of-hospital cardiac arrest: A systematic review. Resuscitation 2009, 80, 297-305. [CrossRef]

35. Kessler, R.C.; Chiu, W.T.; Demler, O.; Walters, E. Prevalence, severity, and comorbidity of twelve-month DSM-IV disorders in the National Comorbidity Survey Replication (NCS-R). Arch. Gen. Psychiatry 2005, 62, 617-627. [CrossRef] [PubMed]

36. Brown, T.A.; Barlow, D.H. A proposal for a dimensional classification system based on the shared features of the DSM-IV anxiety and mood disorders: Implications for assessment and treatment. Psychol. Assess. 2009, 21, 256-271. [CrossRef] [PubMed]

37. Fruzzetti, A.E.; Worrall, J.M. Accurate expression and validating responses: A transactional model for understanding individual and relationship distress. In Support Processes in Intimate Relationships; Sullivan, K.T., Davila, J., Eds.; Oxford University Press: Oxford, New York, NY, USA, 2010; pp. 121-152. 